\title{
A EXPERIÊNCIA HERMENÊUTICA DO JOGO NO ENSINO DO DIREITO AMBIENTAL
}

\author{
Haide Maria Hupffer* \\ Luiz Gonzaga Silva Adolfo**
}

\begin{abstract}
RESUMO
Um dos grandes desafios do ensino do Direito Ambiental nas Faculdades de Direito, hoje, está na descoberta de estratégias que contemplem as possibilidades e modalidades de diálogos entre os diversos paradigmas que sustentam o conhecimento, entre as diferentes ciências, metodologias de ensino-aprendizagem que coexistem em um espaço onde se constroem e se consolidam saberes. Uma orientação docente na área ambiental conduz, inegavelmente, a incentivar o hábito da análise inter, multi e transdisciplinar. $\mathrm{O}$ estudo propõe alguns caminhos para o ensino do Direito Ambiental, fundamentado na experiência hermenêutica do jogo desenvolvido por Heidegger e Gadamer. O jogo, como espaço de diálogo crítico, reflexivo e transdisciplinar, propicia uma relação de ensinoaprendizagem no Direito Ambiental iluminada pela aplicação como um momento, no processo hermenêutico, tão essencial e integral como a compreensão e a interpretação.
\end{abstract}

Palavras-chave: Hermenêutica filosófica. Direito ambiental. Ensino jurídico. Jogo.

\begin{abstract}
One of the greatest challenges of Environmental Law teaching in Law Schools nowadays is the finding of strategies contemplating the possibilities and modalities of dialogue within the many patterns that sustain knowledge, within the different sciences, teaching and learning
\end{abstract}

\footnotetext{
* Doutora em Direito pela Universidade do Valo do Rio dos Sinos (UNISINOS). Professora do curso de Direito e do Mestrado em Qualidade Ambiental da Universidade Feevale/RS. E-mail: haide@feevale.br

** Doutor em Direito pela Universidade do Valo do Rio dos Sinos (UNISINOS). Professor e pesquisador no Programa de Pós-Graduação em Direito na Universidade de Santa Cruz (RS). E-mail: gonzagaadolfo@yahoo.com.br
} 
methodologies coexisting in a space where knowledge is constructed and consolidated. A teaching orientation in the environmental area leads to an incentive to the habit of analyzing inter, multi and transdisciplinarly. This paper proposes some ways for the Environmental Law teaching based on the hermeneutic experience of the game developed by Heidegger and Gadamer. Such game, as a space of critical, reflexive and transdisciplinar dialogue, propitiates a teaching and learning relationship of Environmental Law illuminated by the application as a moment so essential and integral as the comprehension and the interpretation in the hermeneutical process.

Keywords: Philosophical hermeneutics. Environmental law. Juridical teaching. Game.

\section{Considerações Iniciais}

O século XXI assume uma das piores heranças advindas da pósmodernidade: a crise ecológica resultante da degradação dos ecossistemas, poluição pela acumulação de dejetos e resíduos, destruição sistemática das florestas, espécies animais e bioesfera, do esgotamento ou superexploração dos recursos naturais, deteriorização da qualidade de vida e, em especial, a crise da relação homem-natureza e a necessária recuperação do direito fundamental ao meio ambiente equilibrado e à sadia qualidade de vida. Desde os primórdios da civilização, a relação homem-natureza está ancorada na visão antropocêntrica, ou seja, centrada no indivíduo e em seu poder de dominar a natureza, possuí-la, subjugá-la e submetê-la às suas vontades egoístas, consumistas e imediatistas. Descartes é um dos filósofos que abre caminho para separar o ser humano e a natureza. Em sua obra Discurso do método, ele apresenta o homem como senhor e dono da natureza, ao referenciar que:

Elas (as noções gerais relativas à física) fizeram-me ver que é possível chegar a conhecimentos que sejam consideravelmente úteis à vida, e que, em lugar dessa filosofia expeculativa que se ensina nas escolas, se pode achar uma prática, através da qual, conhecemos as diversas matérias dos nossos artesões, as poderíamos empregar do mesmo modo para todos usos aos quais são próprios, e assim tornarmos donos e senhores da natureza (DESCARTES, 1999, p. 94). 
Isso o caracteriza como contemporâneo de uma revolução científica. Descartes não mostrou uma disposição pela natureza, mas uma ordenação para o homem se tornar seu dono e senhor. O filósofo constrói a tese da utilidade da natureza explicada pelo lugar ocupado pelo indivíduo. $\mathrm{O}$ alicerce está no racionalismo, no patrimonialismo e na visão antropocentrista que, depois, é abraçada pelo iluminismo e pelo positivismo.

A sociedade pós-industrial é demarcada pelas incertezas e riscos produzidos pelas gerações passadas e presentes. O Direito Ambiental nasce como resposta jurídica às decisões erradas tomadas no passado, em relação ao meio ambiente e à necessidade de uma recomposição das relações entre o homem e a natureza. Sua finalidade é a proteção e a defesa do meio ambiente em uma dimensão global e intergeracional. Dotado de princípios e normas, caracteriza-se pela perspectiva transdisciplinar e inter-relacional, bem como possibilita avançar para uma compreensão mais ecologicocêntrica, na medida em que se apresenta como alternativa para garantir a qualidade da vida humana e do ecossistema.

Ao se analisarem as principais características que conformam o positivismo exegético-normativista e seu modo de fazer e interpretar, têm-se presente que esse paradigma não sustenta discussões e reflexões sobre a complexidade do Direito Ambiental frente à sociedade de risco e ao direito das futuras gerações a um ambiente ecologicamente equilibrado. O paradigma positivista se perpetuou com a ideia de completude e sistema fechado, com pretensão de regular de forma completa a vida humana; alicerçado na racionalidade lógico-dedutiva, universalmente válido, forma objetivista e tecnicista; sustentado nos dualismos questão-de-direito e questão de fato, esquema sujeito-objeto, teoria e prática; no esquecimento do ser do Direito; assentado no dogma da certeza amparado em verdades definitivas descritas em enunciados lógicos da ordem do dever-ser; priorização de valores, como a previsibilidade e o pensamento lógicodedutivo; identificação do Direito com a lei, ou seja, a primazia da regra em relação às outras fontes do Direito, alienando-o da realidade; Direito como um saber ahistórico e outros aspectos que seguramente contribuíram para agravar a crise de operacionalidade. 
Esses mesmos dogmas estão presentes na educação jurídica. $\mathrm{O}$ modelo positivista de transmissão do saber jurídico, alimentado pelo culto ao "senso comum teórico", encontrou ambiente seguro para se internalizar nos Cursos de Direito. Os ensinamentos que chegam são fragmentados, em pedaços avulsos, sacralizados pelas verdades jurídicas institucionalmente consagradas. Todo este caldo que se sacralizou nas escolas jurídicas não pode ser levado quando se fala em Direito Ambiental. Daí a necessidade de se buscarem novos paradigmas para a compreensão da complexidade do Direito Ambiental, suas inter-relações com outros saberes, a perspectiva do risco e da incerteza científica que estão presentes nas decisões ambientais que devem, necessariamente, ter um olhar para as gerações presentes e futuras, bem como, para o global. Uma das alternativas é a opção pela hermenêutica filosófica que se apresenta como uma condição muito importante para a compreensão do Direito Ambiental: o rompimento de fronteiras.

Para o contexto do presente estudo, entende-se relevante dirigir, inicialmente, a análise do significado paradigmático da hermenêutica filosófica para o ensino do Direito Ambiental, propondo o jogo como estratégica pedagógica alicerçada na hermenêutica fenomenológica de Martin Heidegger e Hans-Georg Gadamer, como matriz privilegiada, capaz de iluminar uma postura crítico-reflexiva perante o Direito Ambiental, avançando na direção da "compreensão do mundo presente" (NICOLESCU, 1999, p. 14). O referencial teórico fundamenta-se na perspectiva da hermenêutica-fenomenológica de Martin Heidegger (a questão do "ser" e do "compreender") e, principalmente, na hermenêutica filosófica de Hans-Georg Gadamer (o "jogo" como autêntica experiência hermenêutica). Por reconhecer a amplitude deste estudo, julga-se que Heidegger e Gadamer podem enriquecer e iluminar o percurso. Suas contribuições teóricas serão relacionadas ao processo de utilização do jogo no ensino de direito ambiental, onde compreender é sempre aplicar. O ensino do direito ambiental, ao assumir um caráter hermenêutico, tem condições de contribuir para o desenvolvimento de competências complexas que a sociedade de risco global está a exigir. Privilegiar-se-á (re)pensar a disciplina de Direito Ambiental a partir da visão de que a interpretação não se autonomiza da compreensão e da aplicação. 


\section{Para além do positivismo: Heidegger e Gadamer e a reflexividade sobre o ser e o compreender}

No final do século XIX e início do século XX, há um despertar para novos horizontes, e a filosofia começa novamente a interrogar-se sobre o papel do ser humano nas configurações do saber, não mais com a visão objetificadora amparada na separação rígida entre sujeito e objeto, que, por sua vez, está fundamentada pela lógica racionalista-iluministapositivista, mas, sim, como um interrogar que quer resgatar a centralidade do homem no processo do saber, como ser-no-mundo e ser-aí. É a partir dessa reflexividade que se dá a "virada" filosófica que vai em direção à linguagem e à consciência histórica, mediadas pela linguística. Essa reviravolta no pensamento filosófico tem seu início na Alemanha, com Friedrich D. E. Schleiermacher, Wilhelm Dilthey, Martin Heidegger e Hans-Georg Gadamer.

Schleiermacher (1999, p. 26) ao buscar descobrir como os professores praticam a interpretação nas faculdades, conclui que muitos contribuem com um tesouro de observações e informações instrutivas, mas que, ao lado desses, "emerge o mais selvagem arbítrio, em parte pela mediocridade pedante e insensível que omite ou totalmente deturpa o mais belo". Essa percepção leva-o a analisar o processo de compreensão, investigando suas possibilidades e seus limites, o que é perspectivado por Schleiermacher "como uma reformulação e uma reconstrução criativa" (BLEICHER, 1989, p. 27).

Dilthey parte da ideia da vida como um dado originário, pois ela contém em si a reflexão e o saber. Para ele, o procedimento das ciências do espírito é a compreensão, que é fruto de uma experiência vivida, que é singular e única. Para o autor, compreender é compreender uma expressão. Toda expressão é a expressão de algo, e esse algo é compreendido quando se compreende a expressão. O significado não é um conceito lógico, mas é entendido como expressão da vida. A vida é uma temporalidade em constante fluir, com significados duradouros, pois ela mesma se autointerpreta e tem estrutura hermenêutica. Em Dilthey, a própria vida é a base verdadeira das ciências do espírito. A filosofia só vale como expressão de vida, e a hermenêutica se dá a partir da fundamentação da filosofia na 
vida (GADAMER, 1999). Para ele, o procedimento das ciências do espírito é a compreensão, que é fruto de uma experiência vivida, que é singular e única. Para se compreenderem as coisas, é preciso reviver a experiência que as originou, pois, assim procedendo, se está vivenciando uma nova experiência. A essência da compreensão interpretativa em Dilthey acontece quando a vida interroga a vida.

Heidegger construiu uma nova matriz teórica que revolucionou a filosofia no século XX e isso o credenciou a ser reconhecido como o maior filósofo do século, responsável pelo grande giro hermenêutico. O fascínio de seu pensar está na pergunta que poucos filósofos se aventuraram a fazer tão explicitamente e tão profundamente: é a pergunta pelo sentido do ser. O objetivo fundante, ao questionar o ser, é devolver ao ser humano a vida. $\mathrm{O}$ que o guiou em suas indagações foi a existência humana, a partir da autoconsciência e da consciência do mundo, pois, para Heidegger, somos seres-num-mundo. Existir é ser.

Ao introduzir o termo Dasein, Heidegger (2002) objetiva pôr novamente a questão do sentido do ser, dando-lhe uma visão mais ampla. Assim, evitou usar o termo homem e sujeito, pois sua intenção era apresentar o "ser" em sua integralidade, em seu caráter histórico-temporal, completamente diferente do homem-sujeito da metafísica moderna, que limitou o ser como mera instrumentalidade. O ser (Dasein) está no mundo como compreensão e como possibilidade, porque se compreende a si mesmo somente por suas possibilidades presentes, passadas ou futuras. O $D a$, o "aí" do Dasein é a abertura ao ser, é o que o ilumina, isto é, a clareira, a Licchtung. O Dasein é o guardião do ser. Tem-se, então, que, quando a iluminação acontece, o ser se entrega ao homem.

Todo o projeto heideggeriano se recusa a um fechamento, a uma completude, a verdades prontas e elaboradas. O fascínio da contribuição de Heidegger está justamente em ele não buscar certezas ou, nas palavras de Inwood (2002, p. XVI), "ele está elaborando os problemas à medida que caminha; o terreno é tão novo e não familiar para ele quanto o é para nós. Ele precisa muitas vezes refazer seus passos e percorrer o mesmo solo de um modo diferente". Acima de tudo, ele é um filósofo que está a caminho; à medida que coloca suas questões filosóficas, Heidegger "levanta questões sempre mais fundamentais, levando-nos a águas cada vez mais profundas" (INWOOD, 2002, p. XCI). 
Para Heidegger (1983, p. 33), o homem que medita deve experimentar o coração incuso do desvelamento. Ao exprimir tal afirmação, sua intenção volta-se para o que o homem tem de mais próprio, que é "o lugar do silêncio que concentra em si aquilo que primeiramente possibilita desvelamento. Isto é a clareira do aberto". Ao fazer essa afirmativa, ele mesmo questiona: abertura para quê? O caminho do pensamento especulativo, como o do intuitivo, necessita da clareira que, para Heidegger, pode ser percorrida. Por sua vez, nela reside "também a possibilidade do aparecer, isto é, a possibilidade de a própria presença presentar-se" (HEIDEGGER, 1983, p. 34).

Somente enquanto ser-aí dá-se Ser. O ai é a clareira, enquanto verdade do próprio ser. Dá-se Ser é o acontecer e o manifestar-se, é o destino do próprio ser que, por sua vez, acontece na clareira do ser. Heidegger (1983, p. 141) destaca esse aspecto para demonstrar sua tese de que, na proximidade, na clareira do $a i$, "mora o homem como o ec-sistente, sem que já hoje seja capaz de experimentar propriamente este morar e assumi-lo". O mestre alemão afirma que o ser ainda permanece muito superficial e que a verdade do ser permanece impensada. Para avançar, é necessário libertar-se do tecnicismo objetificante, pondo-se a caminho para pensar o ser em seu sentido de presentar. Mas, para onde? Heidegger (1983, p. 183) tem a resposta: "Para lá onde já fomos admitidos: ao pertencer ao ser. O ser mesmo, porém, pertence a nós; pois somente junto a nós pode ele ser como ser, isto é, pre-sentar-se".

Assim, Heidegger desnuda a questão da pré-estrutura da compreensão, a faticidade, a diferença ontológica, a dicotomia sujeitoobjeto, o pensar como essência do homem, o mundo enquanto condição pré-compreedida, a clareira e a angústia como disposição privilegiada e uma meditação para ir além das visões reducionistas que enxergam apenas a técnica forjada como estratégia de ensino, oferecendo a fenomenologia como o caminho para o pensar.

Gadamer reabilita seus esses pressupostos e dá um passo além, iniciando um novo paradigma, o paradigma da hermenêutica filosófica, para fundamentar sua teoria de que a interpretação não se autonomiza da compreensão e da aplicação. A pergunta fundamental que vai marcar o pensamento de Gadamer é “como é possível a compreensão?". Ele tematizou 
a compreensão como um constitutivo fundamental do ser como sujeito histórico e linguístico. Com Gadamer, a hermenêutica dá um salto. Ele parte da pergunta pela correta epistemologia das ciências do espírito; entra nos âmbitos da natureza da experiência estética; utiliza o conceito do jogo como fio condutor da explicação ontológica; atravessa o âmbito da história, reabilitando a forma da tradição; eleva a consciência em que a história já está operando para princípio hermenêutico; desenvolve sua concepção do círculo da compreensão: da hermenêutica enquanto experiência e do significado paradigmático da hermenêutica jurídica, em que a compreensão de um caso jurídico implica sempre a aplicação do sentido compreendido.

A questão da compreensão remete, inicialmente, ao "círculo hermenêutico" elaborado por Heidegger. Aqui é necessária uma explicação: Gadamer cria, aprofunda, retoma e aplica o entendimento sobre o círculo hermenêutico, explicando essa circularidade entre o sentido interno do círculo e entre o todo e as partes, onde o acontecer se dá como experiência, salientando que aí se encontra a base de toda a compreensão. O autor, ao associar-se a Heidegger, declara que é a partir da análise de Heidegger que o círculo hermenêutico adquire um novo significado. A preocupação de ambos está centrada na condição de possibilidade e no acontecer do sentido. Conceberam o círculo ontologicamente. É ontológico porque o sujeito está sempre implicado no ato de conhecer e de pensar (ROHDEN, 2002, p. 164).

É a partir daí que Gadamer reelabora a noção de pré-compreensão em uma teoria do pré-juízo, que constitui a orientação prévia da experiência hermenêutica, sustentada pela realidade do ser, que se encontra sempre imerso na história, como um ser-no-mundo. É o pré-julgar e o pré-ver que orientam o juízo e o primeiro olhar. Demonstra-o Gadamer quando defende que o pré-juízo não é o polo oposto a uma razão livre de pressupostos, mas um componente do compreender, ligado ao caráter historicamente finito do ser humano. A compreensão é constantemente guiada e sustentada por pré-juízos, pois eles não podem meramente ser postos de lado; devem, sim, ser sempre colocados em questão para se poder interrogá-los e iniciar um diálogo com a tradição.

D’Agostini (2002, p. 143) reflete, registrando que, cada vez que se intenta interpretar o mundo, depara-se com vontades, intenções, expectativas, preconceitos. Os preconceitos são, também, o a priori para ver 
a realidade, sem os quais a própria realidade pareceria privada de sentido. A contaminação subjetiva do dado é, para D'Agostini, “inevitável, mas é também positiva, oportuna, pois o já saber (de modo preliminar e vago) o que procuro saber é a condição para que me seja possível compreender a resposta". Salienta ainda que o único modo de obter uma compreensão o mais possível objetiva é conhecer os próprios preconceitos e refletir sobre eles, rompendo a resistência, questionando-se, participando conjuntamente e ampliando a compreensão do universo hermenêutico em que se vive. Pretender neutralidade é o principal fator que cega, pois não há saber livre de preconceito, ou seja, o preconceito mais obsecante é o preconceito da ausência de preconceitos (D'AGOSTINI, 2002, p. 143).

Por isso, é importante, no ensino do Direito Ambiental, analisar as pré-condições políticas, econômicas, culturais, sociais e as circunstâncias históricas que formaram o paradigma antropocentrista que tem sustentado a relação homem-natureza até o presente. Não significa basear o conhecimento a partir de uma tradição fechada sobre si mesma, e sim permitir que a compreensão possa se dar como consequência (sugestão para evitar repetição) do estudo desse complexo conjunto de fatores que levou à degradação do meio ambiente e à construção de princípios constitucionais ambientais e legislações nacionais e internacionais que buscam a prevenção de novos danos. Essa é a razão para Gadamer reivindicar que é necessário realizar tal mediação: entender por que os ideais de um Direito do Ambiente - seu compromisso com o ambiente e com um novo modelo de desenvolvimento - foram deturpados por interpretações que reduziram o Direito, dogmática e conceitualmente, a um "sistema normativo prescrito que, já em si mesmo e previamente, define sua unidade e que se propõe impor à realidade humano-social essa sua racionalidade normativa, antecipada e logicamente construída" (CASTANHEIRA NEVES, 2002, p. 25).

É aí que se insere o jogo na perspectiva da hermenêutica como estratégia pedagógica. A lógica do jogo da teoria clássica está associada à lógica da razão, apoiada no raciocínio matemático. Já a lógica presente no jogo como experiência hermenêutica tem seu alicerce na ontologia e permite uma experiência interpretativa.

No campo de estudo do Direito Ambiental, a estratégia do jogo, na perspectiva hermenêutica, aplica-se objetivando que o acadêmico tenha a 
compreensão de como decisões sobre o meio ambiente afetam o equilíbrio do ecossistema para as presentes e as futuras gerações, não apenas sob o olhar do direito, mas, principalmente, observando como especialistas de outras áreas do conhecimento compreendem a demanda ambiental. Nesse sentido, a difícil equação entre desenvolvimento sustentável e equidade intergeracional, em que se propõe conciliar progresso econômico com o direito fundamental das gerações atuais e futuras, pode ser explicada a partir do entendimento de como cada decisão coletiva, empresarial ou individual pode influenciar, positiva ou negativamente, o meio ambiente.

O Direito Ambiental tem essa condição privilegiada de necessitar do contato com outras áreas do conhecimento e, em suas conexões com a sociedade, buscar a reversão do processo formativo, mudar de atitude frente ao problema ambiental, para superar a visão reducionista do positivismo exegético-normativista. É preciso sair das preleções acadêmicas na estrutura de monólogos que ainda vigoram no ensino jurídico, no qual o professor continua ministrando aulas-conferências e o aluno se dispõe a ser um mero ouvinte passivo. Por isso, o jogar de Heidegger não é uma sequência mecânica e lógico-estrutural; mesmo tendo regras, o jogo torna o ser livre.

\section{O jogo em Heidegger: a liberdade se dá quando se compreende o ser como ser-no-mundo, quando a compreensão tem caráter de jogo}

O termo fenomenológico, em Heidegger (1983, p. 302), exprime uma máxima, "as coisas em si mesmas", ou seja, o que se mostra em si mesmo. O essencial, para a fenomenologia, "não consiste em realizarse como movimento filosófico. Acima da atualidade está a possibilidade. Compreender a fenomenologia quer unicamente dizer: captá-la como possibilidade". São essas possibilidades que Heidegger apresenta quando ele trabalha a questão do jogo, a dicotomia sujeito-objeto, o pensar como essência do homem, o mundo enquanto condição pré-compreedida, a clareira e a angústia como disposição privilegiada e uma meditação para ir além das visões reducionistas que enxergam o meio ambiente pela visão antropocêntrica e pelo tecnicismo forjado do positivismo exegéticonormativista, oferecendo a fenomenologia como o caminho para o pensar. 
Em Heidegger, o homem se compreende quando compreende o ser e, ao compreender-se como poder-ser, compreende-se como ser-no-mundo e vice-versa. E isso exige um questionar a si mesmo, questionar a vida e o que se projeta no tempo. A Filosofia é "vida preocupada, dizia Heidegger na conferência sobre Ontologia, é o estar-alerta do Dasein para si mesmo, o que significa antes de tudo, surpreendê-lo onde ele se retrai de si mesmo" (SAFRANSKI, 2000, p. 21).

O que Heidegger mostra é que existe um outro pensar, diferente da lógica da matemática e da corrida desenfreada da racionalidade técnicocientífica que domina a era atual. Seu propósito é o de mostrar como o ser humano é principiante e que há uma outra maneira de pensar sobre o meio ambiente utilizando-se o jogo. Daí que, da hermenêutica de Heidegger, as graves questões ambientais que afetam a natureza e a sociedade podem ser interpretadas quando se consegue ver o mundo como o "jogo da vida". O jogo de que Heidegger fala não é o jogo que exige apenas o seguimento de regras e nem um comportar-se conforme elas.

Por mais paradoxal que isso pareça, a vinculação com as regras do jogo tem um propósito de liberdade num sentido totalmente especial. Jogar, para Heidegger (1999, p. 329), “é um livre configurar, um livre formar, que tem sua própria concordância interna, enquanto esse formar se dá a si mesmo essa sua concordância interna no próprio jogo". A liberdade se dá quando se compreende o ser como ser-no-mundo, quando a compreensão tem caráter de jogo. Quando Heidegger (1999, p. 328) expressa o sentido do ser-no-mundo como jogo da vida, ele quer reafirmar seu conceito de jogo, ou seja, "jogar o ser, abri-lo jogando esse jogo, formá-lo nesse jogo".

Acima de tudo, esse jogo é o mundo da vida que exige que se coloque "o fenômeno do mundo em íntima conexão com a existência mesma, e que se ponha à vista essa constituição básica da existência", a que Heidegger (1999, p. 328) denomina ser-no-mundo. É o ser-no-mundo como jogo, mas não no sentido de inventar um conceito de jogo para depois aplicá-lo à existência ou de que a existência é uma espécie de jogo ampliado. O desafio que Heidegger lança é "obter do fenômeno do jogo uma indicação, uma orientação, um guia que nos permita apreender em seu caráter unitário essa mudança, esse acontecer, esse suceder". Jogar, nesse sentido, é um "ir mais além do ente, um sobrepassar o ente". Para 
o filósofo, "ser-no-mundo tem ido mais além (tem passado ele) do ente e o tem envolto em seu jogo; neste jogar é onde empreende formando-se o espaço, incluso no sentido real e literal, dentro do qual encontramos o ente" (HEIDEGGER, 1999, p. 329).

Aliás, aqui aparece a orientação para avançar na aprendizagem do Direito Ambiental: não um método, e sim caminhos para fortalecer o reconhecimento da força normativa do Estado Democrático de Direito Ambiental e do meio ambiente como um macrobem, alcançando o reconhecimento de que o meio ambiente ecologicamente equilibrado é essencial para a existência digna de todos os seres vivos (visão ecologicocêntrica), no presente e no futuro. Ou seja, o professor tem diante de si a tarefa de empreender caminhos que possibilitem vislumbrar uma clareira para que o futuro jurista integre, no seu agir profissional, o espírito de solidariedade entre as gerações, amparado no caput do art. 225 da Constituição Federal, que rege: "Todos têm direito ao meio ambiente ecologicamente equilibrado, bem de uso comum do povo e essencial à sadia qualidade de vida, impondo-se ao Poder Público e à coletividade o dever de defendê-lo e preservá-lo para as presentes e futuras gerações".

Esse caminho a ser empreendido para a efetividade dos princípios constitucionais ambientais pode ser um privilégio ou a sua angústia. É possível encontrar nele alternativas que possibilitem vivências significativas aos acadêmicos de Direito pela possibilidade de "romper com a 'certeza de si do pensamento pensante' (Selbstgewissheit des denkenden Denken), próprio da filosofia da consciência, e ultrapassar o obstáculo representado pela dualidade sujeito-objeto" (STRECK, 2001, p. 285). Daí dizer que é importante buscar em Heidegger subsídios sobre a difícil tarefa do pensamento, ou seja, pensar sobre as exigências da complexa crise ambiental que se dá no des-velamento de princípios, valores, riscos, incertezas, legislação Constitucional e Infraconstitucional e da política ambiental global.

Uma questão instiga à reflexão: como trabalhar com o jogo para responder ao texto constitucional, enquanto matriz privilegiada de sentido do ordenamento jurídico, que une a conscientização pelo dever de preservação do meio ambiente e o direito fundamental ao meio ambiente ecologicamente equilibrado? Streck (2002, p. 123) responde que o novo paradigma do Estado Democrático de Direito é constituidor, dirigente e programático, visto que o Direito passa a assumir uma nova feição, não mais 
voltado apenas à "proteção do indivíduo, enquanto mônada, pretensamente autônomo (espécie de Barão de Münchausen), mas, sim, à proteção e à implementação dos direitos fundamentais-sociais até então sonegados pelo paradigma liberal individualista-normativista". Essa condição exige estratégicas pedagógicas que indiquem ao intérprete da Constituição o caminho do "pensar" ontológico-historial para ter acesso à linguagem. E a linguagem não é uma terceira coisa que se interpõe entre o sujeito e o objeto; ela é a morada do ser. $\mathrm{O}$ intérprete já está sempre inserido e mergulhado na linguisticidade do mundo e deve libertar-se da interpretação técnica do pensar que, ao longo dos últimos séculos, culminou no abandono do pensar nos cursos jurídicos.

Por isso, é importante o retorno ao jogo desenvolvido por Heidegger, posto que deverá ser adequado constantemente, para evitar o esquema de que há sujeitos e objetos do conhecimento. $\mathrm{O}$ jogo, como apresentado por Heidegger (1999, p. 329), orienta no sentido de trazer o seu elemento configurador, ou seja,

Jogar nunca é, portanto, um comportamento acerca de um objeto, nem em geral é um simples comportamento acerca de..., mas que o jogar do jogo é jogo de jogar (o jogo que se joga e o jogo em que se jogar esse jogo consiste) e, sobretudo e originalmente, uma mudança, um suceder, um acontecer que em si é indivisível e inseparável.

O projeto heideggeriano se recusa a um fechamento, a uma completude, a verdades prontas e elaboradas. Suas contribuições para a temática do ensino de Direito Ambiental estão, justamente, em ele não buscar certezas. Heidegger orienta a buscar respostas à medida que caminha. O Direito Ambiental é um tema novo nas discussões jurídicas. $\mathrm{O}$ modo de trabalhar de Heidegger é não responder com a lógica cartesiana aos questionamentos, e sim elaborar novas questões sempre mais profundas, para nos guiarem por terrenos ainda não explorados. A teoria da sociedade de risco mundial, traduzida por Ulrich Beck (2008) como modernidade reflexiva, incertezas fabricadas, domínio do não saber, distribuição de riscos, irresponsabilidade organizada, entre outros, é um desses terrenos pouco explorados. O jogo, em Heidegger, possibilita refazer os passos e percorrer o solo do princípio da precaução de um modo diferente. 
O Princípio da Precaução vem, justamente, para mostrar que não há certezas científicas, nem validade universal ou rigor matemático para antecipar as ameaças e graves crises que possam causar dano irreversível e riscos incalculáveis ao meio ambiente. E este é o modo de ser de Heidegger: instigar a ver que sempre há questões mais profundas na experiência do pensar. É nesse contexto que Stein $(2002$, p. 34) fala de transcendência ligada à existência, onde o pensar é um modo de ser-no-mundo, porque o "que efetivamente permanecia não resolvido era propriamente a condição do ser humano, enquanto 'formador de mundo', isto é, enquanto um modo de ser determinado a partir da totalidade da condição humana". É sob esta outra lógica que Stein (2004, p. 99) referencia, em suas meditações, o dizer de Heidegger: "A pedra não tem mundo, o animal é pobre em mundo, e o homem é formador de mundo". Heidegger não abandona as outras formas de pensar, mas apropria-se delas de uma maneira original. Para isso, porém, é preciso um salto. Haar (1997, p. 101) diz que esse salto é a passagem "sem sair do lugar" do ente ao ser, é uma possibilidade livre do pensamento; ele revela "onde se situa a verdadeira região onde reside a essência da liberdade".

Heidegger (1969, p. 31) fala que o "obscurecimento do mundo não atinge nunca a luz do Ser"; para pensar, é preciso ter a coragem que germina da exigência do ser, na magnificência do simples. É isso que ele expressa com esta afirmação: "Toda coragem do coração é a ressonância ao apelo do Ser, que reúne nosso pensar no jogo do mundo" (HEIDEGGER, 1969, p. 41). Como ser-no-mundo, o Dasein, que permite o pensar sobre a degradação do meio ambiente, tem consciência de que o ato de pensar, muitas vezes, é uma ação solitária, lenta, que exige paciência e o abandono da compreensão por argumentos lógicos e racionais. Está claro para o filósofo que o pensar também pode ser uma rica meditação em comum, onde, pela experiência e pela convivência, surgem companheiros no ofício (do pensar). Pensar o não pensado traz riscos e perigos, mas esses riscos e perigos, por sua vez, são os que iluminam a humanidade para o encontro com a essência da relação homem-natureza. O filósofo usa exemplos da natureza, como a metáfora do relampejar para mostrar como o relâmpago ilumina e instiga a ver e a olhar. Nesse olhar, o ser encontra sua própria luminosidade, e aí se dá o acontecer no ser mesmo, pois no pensar se realiza a relação do ser com a essência do homem. Assim, a aprendizagem do Direito Ambiental, ao se colocar 
no movimento de compreender, já deve ter compreendido o que quer interpretar. Portanto, compreender tem um caráter antecipatório, pois, para se compreender, precisa-se sempre realizar um projetar, e nisso está a grande descoberta de Heidegger a respeito da pré-estrutura da compreensão. Nesse constante reprojetar, próprio do jogo, acontece o estar aberto à opinião do outro ou do texto. A tarefa da hermenêutica indica que o importante é dar-se conta das próprias antecipações, dos pré-juízos para lidar com os princípios do Estado de Direito Ambiental. É ter humildade para reconhecer que a pesquisa científica, diante da sociedade de risco, não mais pode se pronunciar com certeza. É dar-se conta de que decisões sobre o meio ambiente e as futuras gerações não se limitam a aplicar a lei em si e aos ditames da ciência. É acolher a transdisciplinaridade e o diálogo no modo de ser do ensino do Direito Ambiental, pois são questões que perpassam o mero conhecimento da legislação, mas que lidam com a incerteza científica e a adoção de medidas preventivas e antecipatórias, e não, apenas repressivas.

\section{Gadamer e a experiência hermenêutica do jogo: caminhos para o ensino do direito ambiental}

Hans-Georg Gadamer inicia seu projeto filosófico, partindo da experiência que se dá perante uma obra de arte e a ludicidade do jogo como possibilidade de transformar o ser que está apreciando ou jogando. O que se experimenta é o que a arte tem a dizer, pois quem se permite uma vivência, ao apreciar uma obra de arte, fica com uma posse que é duradoura. Gadamer (1996, p. 136) referencia que se precisa aprender que o "jogador de um jogo de arte não é nenhum mundo substituto ou de encenação em que nos esquecemos de nós mesmos". Para o autor "os mais profundos conhecedores da natureza humana não têm ignorado que a capacidade de jogar é um exercício da mais alta seriedade". Traz, ainda, Nietzsche ao texto, mostrando que, para o autor, "o amadurecimento do homem significa ter reencontrado a seriedade que se tinha quando criança, em jogo". Salienta, ainda, que Nietzsche também sabia o contrário, ou seja, "festejava na leveza divina do jogo o poder da vida e da arte" (GADAMER, 1996, p. 136).

$\mathrm{O}$ jogo, enquanto experiência hermenêutica, encontra seu desenvolvimento mais expressivo em Gadamer. O pensador desenvolve 
a perspectiva dessa atividade, amparado em seu compromisso apaixonado de ser um professor que reflete "sobre o modo como se poderia trazer a uma real atualidade os diversos caminhos filosóficos que se tinha que seguir no ensino, partindo da situação filosófica do presente" (GADAMER, 2002, p. 561). Gadamer, professa que a gênese de sua "filosofia hermenêutica" nada mais é do que a tentativa de explicar, teoricamente, o estilo de seus estudos e de seu ensino. O que Gadamer (2002, p. 563) ensina é, sobretudo, a práxis hermenêutica. "Essa é antes de mais nada uma práxis, a arte de compreender e de tornar compreensível. É a alma de todo ensino que queira ensinar filosofia".

O suporte ontológico da experiência hermenêutica de mundo traz o conceito de jogo desenvolvido por Gadamer. O participante experimenta o jogo como uma realidade que o transcende e compartilha uma mesma condição, que é a relação de pertinência e de distanciamento. O jogo, em Gadamer, é relacionado à experiência hermenêutica e tem a linguagem como meio. $O$ interesse central na compreensão hermenêutica "não é competitivo ao interesse científico-cognitivo quando da explicação de eventos da natureza" (NEVES, 2005, p. 72 e ss.). Sua função é de complementaridade e jamais de competição em relação a quem está com a verdade.

Quando Gadamer traz o jogo como momento da experiência hermenêutica, ele reafirma o caráter lúdico próprio de toda cultura humana. Posiciona-se a favor de que a arte estimula a vida. Para o autor, é possível descobrir formas lúdicas em tarefas humanas vitais, como na relação ensino-aprendizagem, onde ocorrem representações de papéis. Ora, na autêntica experiência lúdica que o jogo propicia, a aplicatio não pode vir separada da intellectio e da explicatio. Assim, para o autor a "estrutura da aplicação, com seu direito de cidadania herdado da hermenêutica jurídica, precisa adquirir um valor paradigmático". O que a reflexão jurídica sobre o meio ambiente faz é descobrir os condicionamentos que estão presentes quando nos empenhamos em esclarecer um princípio, ou uma norma, ou as contribuições das outras ciências, visto que são formadores da sua constituição prévia. Gadamer (2002, p. 131) chama a atenção que isso, em absoluto, não significa que as "ciências do espírito fiquem vegetando como ciências inexatas em toda sua lamentável insuficiência". Ao contrário, para o autor, a compreensão de questões complexas, como, por exemplo, citam-se as envolvidas no Direito ao Ambiente, só é possível 
quando os jogadores colocam em jogo seus próprios preconceitos. Cada jogador possui seu horizonte individual, e todo o compreender na estratégia do jogo representa uma fusão de horizontes. A linguagem é que vai mediar esta distância entre os saberes e os preconceitos de cada jogador. Nela o jogador traz ao jogo o que compreendeu. Em certo sentido, o jogo partilha com a lógica a universalidade da hermenêutica filosófica. Assim, Rohden reconstrói a estrutura do jogo de Gadamer, afirmando que

É lógico por um lado, porque possui regras fixas, universalmente válidas, sem as quais ele não ocorreria. As regras de cada jogo, com suas exigências próprias, são explicáveis e reconhecidas universalmente. Por outro lado, o jogo é ontológico porque nele o sujeito é envolvido como um todo, não apenas do ponto de vista do conhecimento - como um espectador que examina um objeto à distância - mas porque, nele, $\mathrm{o}$ jogador ao jogar realiza uma experiência e revela o seu ser (ROHDEN, 2002, p. 112).

Portanto, a partir dos aportes teóricos de Rohden, a lógica que se busca ao permitir que, no jogar, o jogador realize uma experiência e, com isso, revele seu ser, é uma lógica diferente da metodologia que apenas articula determinações puramente conceituais, racionais, ou seja, um ensino que tem como base puros conceitos e a norma posta na estrutura lógica e funcional de um cartesianismo dogmático do fenômeno jurídico ambiental e da visão antropocêntrica do meio ambiente.

Dessa forma, o evento que se dá na transição do jogo e do jogar permite aprofundar a compreensão até um âmbito que "já não é acessível de um modo imediato, mas só dentro do que ele produz e opera" (GADAMER, 1996, p. 131). É a arte, na perspicaz visão de Gadamer, que propicia esse outro olhar, pois o "assombroso do impulso artístico não é precisamente seu caráter impulsivo, mas o alento de liberdade inerente a sua formação". O jogo, em Gadamer, tem esse interesse especial, pois se trata de uma ação simbólica onde o decisivo não está em realizar algo de utilidade grandiosa, ou de beleza supérflua, ou de estratégia espetacular, mas "em que o produzir humano pode propor-se tarefas assim diversas e proceder segundo planos que se distinguem num momento de livre arbitrariedade" (GADAMER, 1996, p. 131). 
Face ao exposto, questiona-se: como aplicar o modelo estrutural lógico-ontológico desenvolvido por Gadamer ao ensino de Direito Ambiental? O jogo como espaço de compreensão mais ampla e do acontecer do sentido do Direito para o aluno possibilita a transposição para as situações de aprendizagem dos três princípios defendidos por Gadamer, compreensão, interpretação e aplicação? Para responder a essas questões, inicialmente, é essencial permitir ao pensamento a arte de pensar, refletir, criticar e criar, embalado pelo mais puro espírito de liberdade e (des)velamento, descortinando novos horizontes sobre o processo de manipulação do homem no meio ambiente, bem como em relação ao consumo excessivo de recursos naturais de que podem ser considerações os paradoxos da presente civilização.

Assim sendo, nas situações de ensino-aprendizagem, o modelo estrutural de jogo desenvolvido por Gadamer abre o caminho para organizar o espaço da aula em torno de comunidades de aprendizagem que são postas frente a determinados temas ambientais, tendo como atores privilegiados para experiência os três momentos da autêntica experiência hermenêutica: interpretação, compreensão e aplicação. Como é da natureza do jogo, as regras devem ser claras e disponíveis a todos os jogadores.

A pergunta que motiva o jogo na perspectiva da hermenêutica filosófica não é feita para valorar a certeza da única resposta certa que se concretiza na objetificação da realidade, mas sim, para precisar como cada um vai conduzir sua atuação enquanto jogador, apoiando-se no círculo hermenêutico da compreensão, tendo condições, ao longo do jogo, de darse conta de que "é equivocado cindir/separar discursos de fundamentação/ justificação de discursos de aplicação" (STRECK, 2005, p. 8).

O essencial, acompanhando o pensamento de Streck, é a construção da resposta hermeneuticamente adequada, onde o importante é o aprendizado dos alunos como intérpretes, tendo sempre presente que,

Definitivamente, o intérprete não escolhe o sentido que melhor lhe convier. O resultado da interpretação não é um resultado de escolhas majoritárias e/ou produto de convencionalismos. Não se trata, evidentemente, de verdades ontológicas no sentido clássico. Claro que não!

Os sentidos se dão intersubjetivamente. Consequentemente, na medida em que essa intersubjetividade ocorre na e pela linguagem, para além 
do esquema sujeito-objeto, os sentidos arbitrários estão interditados. É por isso que é possível alcançar respostas hermeneuticamente adequadas (corretas) (STRECK, 2005, p. 8).

Daí dizer-se que, no jogo desenvolvido por Gadamer, não há ganhadores e nem perdedores, diferentemente do jogo de competição ou de estratégias que tem seu alicerce na racionalidade, mas um jogo que extrapola a concepção de um método. A regra consiste em empreender o jogo enquanto um caminhar que leve os jogadores a uma ponderação justa para a elaboração de uma resposta hermeneuticamente adequada, ancorada na Constituição. É importante, ao trabalhar com os alunos, recordar que não há uma única, verdadeira, válida e necessária solução para o caso em jogo. A estrutura da ordenação do jogo "faz com que o jogador desabroche em si mesmo" (GADAMER, 1999, p. 179).

O objetivo é como se dá a negociação da decisão hermeneuticamente adequada. Ressalta-se que o jogo é instituído por regras, mas, mesmo sujeito a regras, deixará de ser "jogo se não for livremente jogado. Só joga quem deseja jogar" (ROHDEN, 2002, p. 122). Como intérpretes, a tarefa principal dos jogadores "é descobrir a pergunta a que o texto vem dar respostas; compreender um texto é compreender a pergunta" (BLECHER, 1989, p. 160), tendo presente que a descoberta da resposta hermeneuticamente correta é uma "reconstrução integrativa do Direito, que possibilita a resposta adequada constitucionalmente" (STRECK, 2005, p. 15). No jogo idealizado por Gadamer (1996, p. 136), todos participam, mas de forma diferente, pois, para o filósofo, o mero espectador não existe em absoluto, visto que, "no teatro ou no auditório, no museu ou no isolamento de uma leitura, se enxerga, em uma distância inabordável, a um prazer estético ou formativo. Se malentende a si mesmo".

$\mathrm{O}$ que se busca é o diálogo hermenêutico. Tal aspecto alinha-se com a interpretação oferecida por Castanheira Neves (2003, p. 20):

situação existencial que na experiência jurídica, ou na experiência da realização do direito, será uma específica situação de diálogo - o diálogo aberto e mediatizado pela 'controvérsia' em que se traduz toda a concreta realização do direito.

Compreender não depende de um método. Para Streck (2010, p. 
75), “existe um processo de compreensão prévia (pré-compreensão) que antecipara qualquer interpretação e que é fundamental". O professor é o orientador desse processo e instigará os alunos a momentos de discussão, de comprovação, de afirmação, de fundamentação, de refutação e de decisão. A produção do conhecimento é orientada por perguntas. Conhecimento, aqui, é vivência, e não passividade e conteudismo:

A compreensão se dará a partir da situação de diálogo, e isto significa, em última instância, a partir da dialética de pergunta e resposta, na qual nos entendemos e pela qual articulamos o mundo comum. [...] isso porque a orientação de mundo não se dá apenas no fato de desenvolver-se, entre os dialogantes, pergunta e respostas, mas por proceder das próprias coisas de que se fala (GADAMER, 2002, p. 13).

A busca da resposta hermenêutica adequada pode ser construída na perspectiva do conceito estrutural do jogo desenvolvido por Gadamer. Acredita-se que o exemplo privilegia a experiência hermenêutica, pois exige predisposição de quem quer participar. É como uma aventura, "permite que se sinta a vida no todo, na sua amplidão e na sua força" (GADAMER, 1999, p. 130). O jogo na relação ensino-aprendizagem possibilita ao jogador/ aluno colocar-se perante si mesmo, em risco, visto que lhe propicia autoexperienciar seus saberes, seus não saberes e seus preconceitos e, além disso, instiga-o a desenvolver habilidades de assumir diferentes papéis que são necessários para a compreensão da complexidade ambiental e que, muitas vezes, pela posição de profissionais do direito formados pela lógica racionalista, não lhe são permitidos.

Pode-se afirmar, portanto, que o ensino do Direito Ambiental é profícuo para a aplicação do modelo estrutural lógico-ontológico desenvolvido por Gadamer e aperfeiçoado por Rohden. Ele encontra receptividade nas discussões de Streck para o Direito, a qual, no caso, está vinculada à busca da resposta hermeneuticamente adequada. A tomada de decisões em questões ambientais não permite se fixar apenas nos critérios previamente estabelecidos. Grande parte das decisões nas questões ambientais são negociadas, exigem persuasão, argumentação, diálogo, priorizando a busca de consensos informados. O ensino do Direito Ambiental, alicerçado no jogo em sua dimensão hermenêutica, é mecanismo ambicioso para desenvolver habilidades para implementar estratégicas voltadas para o futuro (seria isso?). Neste contexto, pode-se 
reconhecer o jogo como a autêntica experiência hermenêutica, na prática, em que a aplicação não se autonomiza da interpretação e da compreensão.

\section{Considerações finais}

A estratégia do jogo para o ensino do Direito Ambiental, nas Faculdades de Direito, possibilita um olhar transdisciplinar, pois o jogar de Heidegger e Gadamer facilita a tomada de decisões ao construir diálogos produtivos entre sociólogos, engenheiros, geólogos, matemáticos, economistas, juristas, filósofos, biólogos, entre outros profissionais. Essa experiência reside na oportunidade de cada ciência, com suas teorias e seus paradigmas, participar de decisões que envolvem o meio ambiente e as futuras gerações. Essa proposta possibilita ao docente perceber como o acadêmico compreende as demais áreas do conhecimento e como ele se adapta a uma dada situação. Além disso, essa estratégia pedagógica pode ser aplicada para fundamentar novas ideias, paradigmas, leis, práticas da sociedade e discursos relacionados (mudei a ordem dos termos por causa da concordância) aos problemas ecológicos intergeracionais e ao direito fundamental ambiental, bem como trazer à discussão o fato de que o direito a um ambiente ecologicamente equilibrado é inegociável. Nesse sentido, a partir da participação e do olhar das diversas ciências presentes na experiência do jogo, propicia-se entender o conflito entre o desenvolvimento econômico e o limite possível de negociação dos direitos das futuras gerações.

A organização da aprendizagem da complexidade do Direito Ambiental, por meio do jogo, baseia-se fundamentalmente no diálogo, busca respostas a perguntas que, em geral, são práticas na relação entre conteúdos e áreas de conhecimento e lhes dão significado. Esse pode ser um modo diferente de trabalhar com os acadêmicos a prática-problemática realização do Direito Ambiental, valorizando o resultado dos alunos como algo peculiar e especial de cada um como participante do processo de ensino-aprendizagem.

Gadamer mostra que o jogo, como a obra de arte, não tem a pretensão de demonstrar sua utilidade para algo, mesmo sendo o resultado de um fazer humano que está à disposição para o uso, mas, como a obra de arte, não foi produzido com intento utilitário. O aluno, ao longo dos séculos, foi colocado como objeto do conhecimento, emprestando ao professor a 
condição de sujeito do conhecimento em um ensino em conformidade com o saber do docente.

Daí dizer-se que associar o jogo a estratégias pedagógicas para o ensino do Direito Ambiental é mostrar a maneira original da diferença entre o pensamento do racionalismo e o que Gadamer se propõe a desenvolver. O recurso de ludicidade contribui, seguramente, para que o acadêmico entre na existência da própria aula. De objeto passa a sujeito da aprendizagem, visto que realiza uma experiência hermenêutica. A aula enquanto pura transmissão de conhecimento é algo repetitivo; o jogo enquanto jogo é algo irrepetível, jamais haverá resultado semelhante, pois ele é um fenômeno único em sua manifestação e seu aparecer. $\mathrm{O}$ jogo enquanto modo de ser no ensino jurídico deve ser reconstruído por seus jogadores (alunos e professores). Exige do observador (aluno) participante do jogo que construa algo, que se comprometa, que participe completamente no sentido de dialogar e de manifestar-se, exteriorizando sua compreensão.

Mesmo sendo insuficiente para abranger todas as questões do Direito Ambiental, é possível concluir que o jogo, na perspectiva da hermenêutica filosófica de Gadamer, transcende a mera compreensão, e podem-se encontrar nele elementos significativos de aprendizagem a partir da ideia de buscar a resposta hermeneuticamente adequada, do diálogo, do desenvolvimento de habilidades e competências estratégicas, pois, ao jogar, o acadêmico se implica num justo decidir. Gadamer propicia uma compreensão mais ampla do que a Teoria dos Jogos na sua visão clássica.

Por fim, a intenção da presente pesquisa é mostrar que este é apenas um caminho e, como tal, merece ser analisado e internalizado no Direito, ou seja, não se tem pretensão de oferecer respostas conclusivas. A novidade do jogo como recurso pedagógico e a complexidade da problemática ambiental sequer o permitem. O objetivo do estudo foi, portanto, mais singelo, ao limitar-se a apresentar a hermenêutica filosófica como um paradigma interessante para o ensino do Direito Ambiental.

\section{Referências}

BLECHER, Josef. Hermenêutica contemporânea. Traduzido por Maria Giorgina Segurado. Lisboa: Edições 70, 1989.

BECK, Ulrich. La sociedad del riesgo mundial - Em busca de la seguridad perdida. Barcelona: Paidós, 2008.

CASTANHEIRA NEVES, António. O actual problema metodológico da 
interpretação jurídica. Coimbra: Coimbra, 2003.

D'AGOSTINI, Franca. Lógica do niilismo: dialética, diferença, recursividade. São Leopoldo: Unisinos, 2002

DESCARTES, René. Discurso do método. Traduzido por Maria Ermantina Galvão G. Pereira. São Paulo: Martins Fontes, 1999.

FIANI, Ronaldo. Teoria dos jogos com aplicações em economia, administração e ciências sociais. Rio de Janeiro: Elsevier, 2006.

GADAMER, Hans-Georg. Estética y Hermenêutica. Traduzido por Antônio Gómez Ramos. Madrid: Tecnos, 1996.

. Verdade e método I. Traduzido por Flávio Paulo Meurer. 3. ed. Petrópolis: Vozes, 1999.

. Verdade e método II: complementos e índice. Traduzido por Enio Paulo Giachini. Petrópolis: Vozes, 2002.

HEIDEGGER, Martin. Introducción a la filosofia. Traduzido por Manuel Jeménez Redondo. Madrid: Frónesis Cátedra Universitat de Valencia, 1999. . Meu caminho para a fenomenologia. In: . Conferências e escritos filosóficos. Traduzido e Introduzido por Ernildo Stein. 2. ed. São Paulo: Abril Cultural, 1983. (Os Pensadores).

. Ser e tempo - Parte I. Traduzido por Márcia de Sá Cavalcanti Schuback. 12. ed. Petrópolis: Vozes e Universidade de São Francisco, 2002.

INWOOD, Michael. Dicionário Heidegger. Traduzido por Luísa Buarque de Holanda. Revisão técnica, Márcia Sá Cavalcante Schuback. Rio de Janeiro: Jorge Zahar, 2002, p. XVI.

NEVES, Jordão Horta. As metáforas nas ciências sociais. São Paulo: Associação Editorial Humanitas; Goiânia: Editora UFG, 2005.

NICOLESCU, Bassarab. O Manifesto da transdisciplinaridade. Traduzido por Lúcia Pereira de Souza. São Paulo: TRION, 1999.

PEDROSO, Marcelo Batuíra da C. Losso. Liberdade e irrenunciabilidade no direito do trabalho: estudos dos princípios à Economic Analys of Law aplicados ao Direito do Trabalho. Porto Alegre: Sérgio Antônio Fabris Editor, 2005. 
ROHDEN, Luiz. Hermenêutica filosófica: entre a linguagem da experiência e a experiência da linguagem. São Leopoldo: EdUnisinos, 2002.

SAFRANSKI, Rüdiger. Heidegger: um mestre da Alemanha entre o bem e o mal. Traduzido por Lya Luft. São Paulo: Geração, 2000.

SALGADO, Priscila Mascari. Conciliação como forma de solução de conflitos no Direito: Teoria dos Jogos aplicada à conciliação trabalhista. 2009. 229f. Dissertação (Mestrado em Direito). Faculdade de Direito da Pontifícia Universidade Católica de São Paulo - PUCSP. São Paulo, 2009.

SCHELEIERMACHER, Friedrich Daniel Ernst. Hermenêutica: arte e técnica da interpretação. Traduzido por Celso Reni Braida. Petrópolis: Vozes, 1999.

STRECK, Lenio Luiz. Hermenêutica jurídica e $(m)$ crise: uma exploração hermenêutica da construção do Direito. 3. ed. Porto Alegre: Livraria do Advogado, 2001.

. Jurisdição constitucional e hermenêutica: uma nova crítica do direito. Porto Alegre: Livraria do Advogado, 2002.

- Da interpretação de textos à concretização de direitos: a incindibilidade entre interpretar e aplicar a partir da diferença ontológica (Ontologische Diferentz) entre Texto e Norma. In: Anuário do Programa de Pós-Graduação em Direito - Mestrado e Doutorado. v. 2. São Leopoldo: UNISINOS, 2005.

. O efeito vinculante das Súmulas e o mito da efetividade: Uma crítica hermenêutica. In: COPETTI, André et al. Crítica à dogmática: dos bancos acadêmicos à prática dos Tribunais. Porto Alegre: Instituto de Hermenêutica Jurídica, 2005. p. 83-128.

Data de registro:27/09/2011

Data de aceite:26/10/2012 